\title{
A escrita fora da escola: tecendo um imaginário discursivo
}

DOI: http://dx.doi.org/10.21165/el.v48i3.2325

\section{Aldimeres Ferraz da Silva' \\ Eliana Maria Severino Donaio Ruiz ${ }^{2}$}

\section{Resumo}

Este artigo se configura como recorte de uma pesquisa maior, na qual buscamos responder a seguinte pergunta: qual é o imaginário discursivo acerca da escrita na contemporaneidade? Fundamentando-nos na Análise de Discurso de orientação francesa, lançamos mão de entrevistas semiestruturadas para analisarmos dizeres de sujeitos inseridos nas formações sociais escolar (professores e alunos de vários níveis) e extraescolar (jornalistas, escritores e publicitários). No presente trabalho, especificamente, focalizamos os dados obtidos junto ao universo extraescolar, num cruzamento interdiscursivo de sujeitos em diferentes posições enunciativas. Nosso gesto interpretativo analítico revelou a recorrência das seguintes representações acerca da escrita: prática que pressupõe conhecimento via leitura; objeto de valor utilitário; instrumento de poder; prática dependente do leitor e modalidade de língua veiculada pela internet.

Palavras-chave: escrita; universo extraescolar; imaginário discursivo.

1 Universidade Estadual de Londrina (UEL), Londrina, Paraná, Brasil; aldimeresf@gmail.com; https://orcid.org/0000-0003-0446-549X

2 Universidade Estadual de Londrina (UEL), Londrina, Paraná, Brasil; elianaruiz@uel.br; https://orcid.org/0000-0002-7169-8464 


\section{La escritura fuera de la escuela: tejiendo un imaginario discursivo}

\section{Resumen}

Este artículo se configura como recorte de una investigación más grande, en la que buscamos responder la siguiente pregunta: ¿Cuál es el imaginario discursivo acerca de la escritura en la contemporaneidad? Fundamentándonos en el análisis de discurso de orientación francesa, nos basamos en entrevistas semiestructuradas para analizar las palabras de los sujetos insertados en las formaciones sociales escolar (profesores y alumnos de varios niveles) y extraescolar (periodistas, escritores y publicitarios). En el presente trabajo, específicamente, enfocamos los datos obtenidos junto al universo extraescolar, en un cruce interdiscursivo de sujetos en diferentes posiciones enunciativas. Nuestro gesto interpretativo analítico reveló la recurrencia de las siguientes representaciones acerca de la escritura: práctica que presupone conocimiento por lectura; objeto de valor utilitario; instrumento de poder; práctica dependiente del lector; y modalidad de lengua transmitida por internet.

Palabras claves: escritura; universo extraescolar; imaginario discursivo.

\section{Introdução ${ }^{3}$}

Ao perscrutarmos as representações de escrita no âmbito do universo extraescolar, analisando dizeres de sujeitos que utilizam a escrita em seu cotidiano (jornalistas, escritores e publicitários), pudemos constatar o quanto ela é fundamental na nossa interação social. Confirmamos também a ideia sustentada por Auroux (1998) sobre grafematização, uma vez que a tecnologia da escrita fundamenta a organização da sociedade: o tempo todo recorremos a essa modalidade da língua para fins diversos, daí sua representação como objeto de valor utilitário, conforme mostraremos. Compreendemos, ainda, que a escrita reflete nossa própria organização social assimétrica, constituindo-se como instrumento de poder, dominação e segregação, numa interdependência com a leitura e o conhecimento. Neste artigo, então, trazemos algumas das reflexões arroladas em nossa pesquisa, constituindo um recorte da leitura analítica que vimos efetuando a partir do quadro teórico-metodológico da Análise de Discurso francesa.

\section{Escrita, letramento e AD francesa}

As práticas do oral/falado e do letrado/escrito em nossa sociedade estão, obviamente, relacionadas às relações sociais intrínsecas do ser humano, constituindo-se como processo sócio-histórico de utilização da língua (MARCUSCHI, 2001). Ambas as práticas

3 Trabalho apresentado no $66^{\circ}$. Seminário do GEL sob o título A escrita segundo jornalistas: tecendo um imaginário discursivo fora da escola. 
não podem, pois, ser pensadas fora de uma perspectiva que considere as questões sociais, culturais, políticas, econômicas e cognitivas envolvidas para além de aspectos meramente linguísticos. Nesse sentido, a alfabetização, por exemplo, estaria apenas no domínio da tecnologia da língua, o que nos leva a aproximá-la do conceito de língua imaginária de Orlandi (1988, p. 28): "língua [enquanto] sistema, normas e coerções".

Alfabetização e letramento são conceitos tecnicamente relacionados, mas não interdependentes, já que um sujeito pode não dominar o código formal da língua, mas ainda assim participar de práticas de letramento (SOARES, 1998). Desde que nascemos, convivemos com essas práticas, algumas mais escolarizadas do que outras, que "são aspectos não apenas da cultura, mas também das estruturas de poder numa sociedade" (KLEIMAN, 1995, p. 38). Conforme pontua Auroux (1998, p. 68), a escrita "só aparece (e se mantém) em sociedades fortemente hierarquizadas e entretém desde sua origem (e sobretudo na sua origem) relações muito estreitas com as diversas instâncias de poder que as sociedades humanas conhecem". Por essa razão, o letramento compreende

[...] um conjunto flexível de práticas culturais definidas e redefinidas por instituições sociais, classes e interesses públicos em que jogam papel determinante as relações de poder e de identidade, construídas por práticas discursivas que posicionam os sujeitos por relação à forma de aceder, tratar e usar os textos e os artefactos e tecnologias que os veiculam e possibilitam. (DIONÍSIO, 2007, p. 98).

Vai daí a escrita se constituir como o "arame farpado mais poderoso para bloquear o acesso ao poder" (GNERRE, 1991, p. 22), razão pela qual as práticas e os eventos de letramento observados pelo modelo ideológico (STREET, 1984) são pensados em "relação às estruturas culturais e de poder que o contexto de aquisição da escrita na escola representa" (KLEIMAN, 1995, p. 39).

Outro aspecto a se pontuar é que nossa sociedade é fundamentalmente organizada pela escrita, cujo modo heterogêneo de constituição (CORRÊA, 2004) a faz interdependente da leitura e do conhecimento. Além do quê as práticas de utilização da língua se constituem como processos discursivos diversos "cuja história é feita de fartura e movimento [...] não podendo ser contida no arcabouço de sistemas e fórmulas" (ORLANDI, 1988, p. 34).

Assim, as práticas sociais e situadas de letramento são constituintes da identidade do sujeito, de modo que, ao interagir socialmente, este assume determinados posicionamentos em meio a relações ideológicas e de poder. Por isso a ideia de neutralidade é totalmente imprópria quando aplicada às práticas de letramento, já que estas estão balizadas por questões sociais e ideológicas. Elas representam "os modos culturais em geral de utilização da linguagem escrita das quais as pessoas fazem uso em suas vidas" (BARTON; HAMILTON, 2000, p. 7, tradução nossa), configurando-se como práticas não observáveis "de comportamento, já que envolvem valores, atitudes, sentimentos e relações sociais" (FISCHER, 2007, p. 28). 
Numa perspectiva discursiva, a escrita se constitui como "espaço de articulação entre língua e história, discurso e sujeito" (AGUSTINI;GRIGOLETO, 2008, p. 147), de modo que os sentidos de um texto emergem da interação entre "sujeito e escrita, escritor e texto" (LAGAZZI-RODRIGUES, 2010, p. 90). Em sua constituição, o texto estabelece relações com outros textos e com outros discursos, sendo totalmente clivado pelo interdiscurso e, assim, "fortemente atravessado por diferentes subjetividades que nele fazem ressoar diferentes sentidos em diferentes formações discursivas" (INDURSKY, 2010, p. 72). Desta forma, entendemos a escrita como um modo de relação social por meio do qual os sujeitos, atravessados ideologicamente, assumem determinadas posições ideológicas.

É pensando nessas questões que apresentaremos, na sequência, os aspectos de cunho metodológico de nossa pesquisa.

\section{Aspectos metodológicos}

Nossa pesquisa é de cunho qualitativo e de base epistemológico-interpretativista, sendo que o material de análise foi gerado e coletado por meio de entrevistas semiestruturadas, pensadas através do "mecanismo da antecipação" (ORLANDI, 2007), por meio do qual elaboramos roteiros de questionamentos direcionados a cada grupo de sujeitos investigados, possibilitando uma conversa sobre a escrita, nosso tema de investigação. Ao buscarmos representações atuais de escrita em nossa sociedade, entrevistamos sujeitos de diferentes posições sociais e empíricas, inseridos no universo escolar e extraescolar de utilização da linguagem. Contudo, no presente trabalho, trazemos um recorte, apresentando parte da análise dos dados referentes especificamente ao universo extraescolar, num cruzamento entre os dizeres de quatro jornalistas, quatro escritores e dois publicitários. Tendo em vista a proteção da identidade dos sujeitos, as entrevistas foram identificadas apenas pelas iniciais do nome de cada entrevistado.

Organizamos nossa análise em recortes discursivos (RD) enumerados de 1 a 7 , conforme figuram ao longo deste texto. Para a transcrição das entrevistas, utilizamos algumas das indicações propostas por Marcuschi (1986): (+) para pausas; ( ) para dúvidas ou sobreposições; MAIÚSCULA para ênfases; /.../ indicação de transcrição parcial ou interrupção e :: para alongamento de vogal. Assim, em busca de respostas à nossa pergunta de pesquisa (Qual é o imaginário discursivo acerca da escrita na contemporaneidade?), apresentaremos, a seguir, a leitura analítica empreendida.

\section{0 imaginário sobre a escrita fora da escola}

Após uma leitura inicial do material bruto de análise (as transcrições das gravações das entrevistas semiestruturadas), organizamos nossos recortes discursivos em um único 
eixo temático que denominamos "Escrita"4 e que subdividimos em três categorias gerais de representações, organizadas da mais para a menos recorrente no corpus, às quais denominamos: Letramento; Língua Imaginária x Língua Fluida; Ensino/Aprendizagem. Neste artigo, apresentaremos apenas a análise dos recortes discursivos que se encaixam na categoria Letramento, dentro da qual percebemos a predominância de diferentes imaginários discursivos acerca da escrita: prática que pressupõe conhecimento via leitura; objeto de valor utilitário; instrumento de poder; prática dependente do leitor; e modalidade de língua veiculada pela internet.

Passemos aos recortes discursivos.

Em RD1 a seguir, temos a fala do sujeito $F L$ (jornalista) ${ }^{5}$, em resposta, respectivamente, às questões $n^{0} 2$ e $n^{0} 3$ do roteiro de entrevistas:

(RD1) FL (Jornalista):

P: Como você vê a relação entre leitura e escrita?

FL: Ah (+) escrita e leitura dependem uma da outra né (+) quando (+) quanto mais a gente lê (+) melhor a gente escreve e fala (+) isso é fato né (+) É essencial ler para que você possa produzir um texto $(+)$ porque a leitura te ajuda a qualificar sua escrita (+) ajuda a ampliar seus conhecimentos /.../

P: Ahan (+) e em quais contextos e com qual finalidade você utiliza a escrita em seu dia a dia?

FL: Bom (+) como eu sou jornalista e professor (+) leio e escrevo diariamente provas $(+)$ reportagens $(+)$ etc. $(+)$ Eu trabalho no colégio /.../ aqui em ... (+) também sou jornalista $(+)$ trabalhei um bom tempo na /.../ (+) hoje tenho um portal de notícias culturais $(+)$ então não tem como fugir disso $(+)$ eu escrevo diariamente.

4 Denominamos provisoriamente "Escritor" o outro eixo de nossa pesquisa, já que nosso projeto prevê investigar, também, as representações acerca do produtor de textos na atualidade.

5 FL é formado em Jornalismo e Ciências Sociais. Atuou como repórter cultural, crítico gastronômico e chefe de redação. Foi, ainda, produtor de uma emissora de televisão. Atualmente leciona Filosofia e Sociologia.

6 Questão $n^{\circ}$ 2: Em que contextos e condições você utiliza a escrita? E para que fins você a utiliza em seu dia a dia? Questão n 3 : Você acredita que houve mudanças quanto ao papel da escrita em outros tempos/culturas e na contemporaneidade? Se houve mudanças, qual o papel da escrita nos dias atuais? 
Realizando um movimento de compreensão que caminha da constituição dos sentidos (interdiscurso) à sua formulação (intradiscurso), percebemos, primeiramente, como a própria pergunta que dirigimos ao sujeito acabou configurando seu dizer. Identificamos, assim, a presença de elementos pré-construídos que compõem a memória discursiva do sujeito atravessado ideologicamente - tanto entrevistado quanto entrevistadora. Assim, na fala de FL (jornalista) emerge a ideia de haver uma relação intrínseca entre escrita e leitura, num acionamento da memória discursiva, por meio do pré-construído quanto mais lemos, melhor escrevemos. Esses dizeres, já ditos por alguém em algum lugar e em outro momento histórico, significam de determinada maneira nas palavras de FL. Também para ele, a leitura e a escrita caminham juntas, em um processo complementar, segundo o qual um número expressivo de práticas (representado na fala do sujeito pelo advérbio de intensidade mais) pode conduzir ao aprimoramento do resultado (representado pelo advérbio de modo melhor); ou seja, "quanto mais [a pessoa] ler, melhor irá escrever e falar". As expressões quanto mais e melhor, utilizadas pelo sujeito, suspendem a evidência de que o domínio da escrita pode ser alcançado por meio da prática da leitura e do seu exercício contínuo (leio e escrevo diariamente).

A par disso, a afirmação de que a leitura ajuda a qualificar a escrita e a ampliar conhecimentos é outro elemento pré-construído na fala de FL. Sabemos que a ampliação de conhecimentos por meio da leitura é ponto pacífico nos estudos da linguagem. Antunes (2003, p. 70), por exemplo, pontua que os conhecimentos ampliados pela leitura são essenciais para aquele que escreve, já que "[...] para escrever bem, é preciso, antes de tudo, ter o que dizer, conhecer o objeto o qual vai discorrer". No entanto, ao produzir seu discurso, o jornalista FL se fundamenta no senso comum. Aliás, isso se nota, inclusive, na fala de outros sujeitos entrevistados.

No próximo recorte discursivo, por exemplo, referente às respostas do sujeito PD (escritor) $^{7}$ às mesmas perguntas $\mathrm{n}^{0} 2$ e $\mathrm{n}^{0} 3$ do roteiro, notamos o acionamento da memória discursiva sobre o mesmo aspecto de interdependência entre escrita e leitura:

(RD2) PD (Escritor)

P: Como você vê a relação entre leitura e escrita?

PD: Há uma relação obviamente essencial (+) entre leitura e escrita $(+)$ já que $(+)$ a escrita só existe para ser lida (+) assim como a fala só existe para ser ouvida $(+)$ aliás (+) a linguagem é filha da cooperação entre fala e escuta.

P: Certo. E em que contextos e com qual fınalidade você utiliza a escrita em seu dia a dia?

7 PD é escritor: romancista, contista, cronista, poeta, jornalista e publicitário, ganhador do Prêmio Jabuti. 
PD: No dia a dia (+) quase não uso escrita $(+)$ pois não digito em celular $(+)$ digito apenas as crônicas para jornais e as postagens para Facebook $(+)$ e $(+)$ claro $(+)$ o que estiver escrevendo no momento $(+)$ romance ou seja o que for $(+)$ mas isso não pode ser visto como escrita do dia a dia (+) não? / .../

Ao dizer que há uma relação obviamente essencial entre leitura e escrita, PD (escritor) se apoia igualmente no mesmo pré-construído, argumentando que uma é produzida em função da outra. De fato, Orlandi (2011) pontua a existência de uma relação dinâmica de interação entre leitor e escritor: "embora, de fato, o momento da escrita de um texto e o momento de sua leitura sejam distintos, na escrita já está inscrito o leitor e, na leitura, o leitor interage com o autor do texto" (ORLANDI, 2011, p. 180). Tal interdependência e essencialidade podem ser pensadas também em termos de sentido, já que, para Orlandi (2011, p. 180) não há sentido isolado na escrita/escritor, tampouco na leitura/leitor; estes são produzidos no "espaço discursivo dos interlocutores". O texto é, então, como diz, uma "totalidade de natureza intervalar", uma unidade de análise essencialmente afetada pelas condições de produção.

Também conforme Indursky (2010, p. 69), o texto se configura como um espaço discursivo e não como um objeto fechado em si mesmo, "pois ele estabelece relações não só com o contexto, mas também com outros textos e com outros discursos". Sobre isso, Orlandi explica que a dinâmica de interação entre falante e ouvinte, autor e leitor é o processo pelo qual se produz o texto enquanto unidade e centro comum, sendo que a leitura passa a ser pensada como um confronto de interlocução dentro de um espaço discursivo. Assim, na produção de sentidos, o leitor real interage, debate e confronta ideias com o leitor virtual, já constituído no momento da escrita: "se pensamos a escrita como se constituindo na interação, podemos observar o jogo existente entre o leitor virtual e o leitor real" (ORLANDI, 2011, p. 185).

Justifica-se, pois, segundo os estudos da linguagem no âmbito da $A D$, que tanto $F L$ (jornalista) como PD (escritor) compreendam a escrita como fortemente relacionada à leitura, muito embora tal imaginário, calcado no senso comum ("quanto mais lemos, melhor escrevemos" e "se escrevemos é para que alguém leia; se lemos é porque alguém escreveu") tem sua gênese na escola. Apesar de estarem localizados, nesta pesquisa, no que chamamos de formação social extraescolar, ambos os sujeitos, jornalista e escritor, ainda que em posicionamentos enunciativos diferentes, passaram pela escola, em sua trajetória de vida, antes de assumirem profissionalmente as posições física e empírica de jornalista e escritor, respectivamente. Além disso, é importante considerar que FL (jornalista) atua também na instância escolar, como professor da disciplina de Sociologia em um colégio particular. E, a despeito de entendermos que as práticas sociais de leitura e de escrita precedem a inserção do sujeito na educação formal, a escola se constitui como uma das principais agências de letramento, local de incentivo, exercício e aprimoramento de tais práticas, onde aprendemos questões ideológicas a elas atreladas, 
como, por exemplo "se escrevo é para que alguém leia", seja este alguém um leitor real o próprio professor, como ocorre na maioria das vezes - seja um leitor virtual. Configurase, assim, a emergência de uma primeira representação no corpus analisado: a de escrita como prática que pressupõe conhecimento via leitura.

A par disso, percebe-se que, enquanto para FL (jornalista), a escrita é entendida como uma necessidade de prática diária, configurada pela produção de variados gêneros discursivos- como eu sou jornalista e professor (+) leio e escrevo diariamente provas (+) reportagens (+) etc. $(+)[. .$.$] hoje tenho um portal de notícias culturais -, para PD (escritor)$ a escrita é pensada especificamente como a escrita literária por ele produzida, não a empregada diariamente com fins utilitários (mas isso não pode ser visto como escrita do dia a dia (+) não?). Dessa forma, PD (escritor) se "esquece" de que a escrita, de inúmeras maneiras, faz parte de seu dia a dia (quase não uso escrita), selecionando para nossa conversa apenas a que Ihe configura uma identidade de escritor literário.

Vamos lembrar que o sujeito, para a AD, não é o indivíduo, sujeito empírico, mas o sujeito do discurso, aquele que carrega consigo marcas do social, do ideológico, do histórico, tendo, contudo, a ilusão de ser a fonte do sentido. Em "Semântica e Discurso", Pêcheux (1995 [1975]) afirma que o lugar do sujeito não é vazio, mas preenchido pelo que chama de forma-sujeito: o sujeito do saber de uma determinada Formação Discursiva (FD). É por meio dessa forma-sujeito que nos inscrevemos em uma determinada FD, com a qual nos identificamos e que nos constitui enquanto sujeitos do discurso. Nesse processo, "a forma-sujeito tende a absorver-esquecer o interdiscurso no intradiscurso, isto é, ela simula o interdiscurso no intradiscurso, de modo que o interdiscurso aparece como o puro 'já dito' do intradiscurso, no qual ele se articula por 'correferência'"' (PÊCHEUX, 1995 [1975], p. 167). Deste modo, a forma-sujeito opera uma incorporação-dissimulação dos elementos do interdiscurso, o que aponta para o efeito de unidade/evidência do sujeito efeito uma vez que essa unidade é apenas imaginária.

Por isso, nos recortes mencionados, PD (escritor) assume a posição-sujeito de escritor de obras literárias, inserindo-se em determinada FD e, portanto, selecionando determinados vocábulos e ideias para a construção de seu discurso. Do mesmo modo, FL (jornalista) assume as posições-sujeito de jornalista e professor, afırmando que utiliza a escrita para diversas situações de sua rotina. Dessa forma, parece-nos emergir, na materialidade linguística investigada, a recorrência de uma segunda representação: a de escrita como objeto de valor utilitário, necessário para ambos os sujeitos atuarem socialmente por meio da linguagem, seja para produzir jornalismo, seja para produzir literatura, ou, ainda, para dar conta das demais necessidades cotidianas de comunicação (escrita do dia a dia).

Sobre esse aspecto utilitário da escrita, Auroux (1998, p. 72-73) pontua o seguinte: 
Vivemos em uma sociedade grafematizada. Se não se sabe ler é difícil pegar o metrô; será preciso aprender cada percurso, localizar-se pelo cenário, pelas cores e pelos odores, como se faz no campo ou na floresta, mas o metrô não é propício para isso. Não nos localizamos em nosso espaço social em função dos caminhos que nossos pés percorreram, dos musgos que crescem nas árvores, das rochas e dos rios que nossos olhos enxergaram, nem mesmo das estrelas, mas utilizamos guias e mapas, lemos nomes de ruas e painéis de sinais. A grafematização está em crescimento constante [...] é um processo através do qual os seres humanos utilizaram progressivamente elementos do meio externo para significar e comunicar. A invenção da escrita consistiu em integrar a linguagem humana ao universo dos signos gráficos, abrindo a este último possibilidades quase ilimitadas: uma sociedade não é verdadeiramente grafematizada se não possui escrita.

É por isso que os sujeitos FL e PD apontam, em seus dizeres, para os variados usos da escrita e as diversas práticas de letramento existentes. Dionísio (2007) lembra que tais práticas, definidas e redefinidas por fatores advindos das instituições sociais, classes e interesses públicos, constituem relações de poder e de identidade. Os vários usos da leitura e da escrita são capazes de posicionar os sujeitos "por relação à forma de aceder, tratar e usar os textos e os artefatos e tecnologias que os veiculam e possibilitam" (DIONÍSIO, 2007, p. 98). Essa questão do poder posta pela escrita se evidencia no próximo recorte discursivo, no qual temos a fala do sujeito $\mathrm{RL}$ (escritor) ${ }^{8}$ em resposta a questão $\mathrm{n}^{\circ}$ 1 do roteiro de entrevista: ${ }^{9}$

(RD3) RL (escritor):

P: Fale um pouco sobre o que é a escrita pra você:

RL: / .../ então (+) aos poucos (+) a escrita foi se tornando pra mim uma outra libertação (+) ou seja (+) primeiro foi a leitura como uma libertação $(+)$ porque eu percebi que eu podia dominar o mundo com a leitura $(+)$ tudo estava a meus pés $(+)$ eu podia pegar uma enciclopédia e aprender qualquer coisa $(+)$ eu podia pegar um livro sobre cosmologia e aprender qualquer coisa (+) eu podia sentar na frente de um documentário e aprender tudo aquilo que aquele documentário trazia $(+)$ eu percebi que eu podia domar o mundo só com a leitura (+) percebi isso logo na primeira vez que aprendi a ler (+) porque percebia desde sempre que os adultos que melhor se impunham no mundo são aqueles que de algum modo aprenderam a ler e a interpretar o mundo $(+)$ de algum modo (+) aprenderam e encontraram

8 RL é escritor, poeta e crítico literário, ganhador do prêmio Literário $A B L$, na categoria "Ensaio e Crítica Literária". Professor adjunto na área de Literaturas de Língua Portuguesa em uma universidade pública do Estado do Paraná.

9 Questão nº 1: Fale um pouco sobre o que é a escrita pra você. 
alguma fórmula para ter um lugar ao sol (+) e eu percebia que na maior parte dos casos isso estava ligado ao poder que tinham com a palavra $(+)$ ao poder $(+)$ ao modo como usavam a palavra $(+)$ pra transmitir aquilo que sabia $(+)$ aquilo que 0 saber acumulou $(+)$ e a primeira pessoa que me fascinou nesse sentido foi o meu avô $(+)$ que era um homem leigo (+) que tinha apenas a quarta (+) quinta série $(+)$ mas era um profundo leitor de livros de curiosidade (+) de almanaques e da Bíblia $/ \ldots /$

Da fala de RL (também escritor), emergem questões que envolvem as relações de poder suscitadas pelas práticas sociais de letramento. Percebe-se o deslizamento de sentido, demarcado pelo efeito metafórico, no qual a escrita é vista pelo sujeito não mais como qualquer outra coisa, senão como libertação (a escrita foi se tornando pra mim uma outra libertação). Conforme Gnerre (1991, p. 5), utilizar a linguagem escrita e/ou falada, não consiste em apenas transmitir conteúdos e informações, mas, sobretudo, "comunicar ao ouvinte a posição que o falante ocupa de fato ou acha que ocupa na sociedade em que vive". Desse modo, compreendemos que a linguagem (referenciada por RL através dos termos leitura e escrita) carrega consigo uma carga valorativa significativa, constituindose como um instrumento de poder (libertação), por meio do qual os indivíduos conseguem assumir, ou não, determinadas posições na estrutura social.

Isso porque, assumindo a posição-sujeito de escritor de obras literárias, e apresentandose, assim, como íntimo conhecedor e apreciador da língua, $R L$ (escritor) seleciona e discursiviza algumas palavras e expressões que configuram o deslize, o efeito metafórico por meio do qual suspendemos a evidência de que a leitura e a escrita não apenas são práticas de linguagem interdependentes, mas, sobretudo, instrumentos de dominação e até mesmo de segregação social. Conforme ensina-nos Gnerre (1991, p. 22), a linguagem se constitui como o "arame farpado mais poderoso para bloquear o acesso ao poder", e isso é perceptível na fala de RL,ao eleger as seguintes palavras e expressões: dominar, a meus pés, domar, impunham, lugar ao sol e poder. Por meio delas, suspendemos a evidência de que aqueles que têm o privilégio de saber ler e escrever, ou que ao menos minimamente exercem tais práticas em suas vidas, tornam-se "livres das amarras" (libertação) que bloqueiam o acesso do indivíduo ao poder.

Quando RL diz "eu podia dominar o mundo com a leitura", evidencia-se que, na outra face daquele que é cerceado, dominado pelo poder, está aquele que domina e que posiciona os demais em termos de inferioridade ("tudo estava a meus pés"). Afinal, uma das principais finalidades da escrita, como afirma Tfouni (2010, p. 13), pode não ser simplesmente difundir conhecimentos e ideias, mas, sobretudo, ocultá-las de quem não Ihe tem acesso, isto é, "para garantir o poder àqueles que a ela têm acesso". Não há, pois, neutralidade nas práticas situadas de leitura e de escrita, uma vez que elas são constituintes da identidade do sujeito, já que, ao interagir socialmente, o indivíduo é interpelado em sujeito, assumindo determinadas posições em meio às relações ideológicas e de poder. 
Em consulta ao dicionário, verificamos que o vocábulo dominar pode significar: "1. Exercer autoridade, poder, influência ou domínio sobre. 2. Reprimir. 3. Preponderar, predominar. 4. Saber [...]" (FERREIRA, 2010, p. 265). E o termo domar pode significar: "1. Domesticar. 2. Subjugar, sujeitar. 3. Reprimir" (FERREIRA, 2010, p. 264). Isso nos leva a perceber "o jogo entre o mesmo e o diferente", como diz Orlandi (2011, p. 116), nos seguintes trechos de RL (escritor) em RD3: "eu podia dominar o mundo com a leitura /.../ eu podia domar o mundo só com a leitura".

Nestas formulações, notamos o processo linguístico parafrástico e polissêmico, por meio do qual o sujeito constrói seu discurso de forma a enfatizar que a leitura (e também a escrita) são, antes de tudo, fortes instrumentos de poder e dominação social. Percebemos o deslizamento de sentido que vai do termo dominar ao termo domar, aludindo que, ao dominar o mundo por meio da linguagem, é possível que o sujeito não apenas exerça seu poder sobre o outro, mas, principalmente, domestique, subjugue, reprima esse outro supostamente "inferior" sócioideologicamente. Isso nos leva a compreender por que os sentidos do discurso de RL caminham para a evidência de que a leitura e a escrita têm forte poder libertador e, ao mesmo tempo, segregador.

Conforme Auroux (1998), a escrita se configura como uma tecnologia diretamente relacionada à organização das sociedades, visto que é por meio dela que o sujeito também exerce seu poder. Contudo, é preciso ponderar que isso que chamamos de poder não se restringe apenas à opressão ou segregação de outros, pois, conforme nos ensina Foucault (2004, p. 193), "o poder não é algo que se possa dividir entre aqueles que o possuem e o detêm exclusivamente e aqueles que não o possuem e lhe são submetidos": por ser uma relação de forças que se encontra presente, e em constante movimento, em todos os espaços sociais, sejam eles públicos ou privados, gerando tensões que se expressam em toda relação, "o poder está em toda parte". De maneira que o poder advindo do domínio da leitura e da escrita se configura, também, como a possibilidade de proporcionar mudanças nas relações humanas: "a escrita muda qualitativamente a natureza das ligações sociais e, porque torna possível a escrita da lei e da ciência, ela faz nascerem novas formas de liberdade humana" (AUROUX, 1998, p. 69).

Explica-se, assim, por que RL (escritor) constrói seu discurso discorrendo sobre as possíveis formas de liberdade humana possibilitadas pela leitura e escrita, como a própria interpretação do mundo: "os adultos que melhor se impunham no mundo são aqueles que de algum modo aprenderam a ler e a interpretar o mundo". O vocábulo impor pode significar: "1. Tornar obrigatório ou indispensável. [...] 3. Fixar, estabelecer. [...] 8. Fazer-se aceitar. 9. Determinar a si mesmo" (FERREIRA, 2010, p. 412). Novamente percebemos, nesses dizeres, o deslizamento de sentido por meio do qual emerge a evidência de que os sujeitos que alcançam a "libertação das amarras" que os distanciam do poder, por meio da leitura e da escrita, são sujeitos privilegiados pela aquisição do conhecimento, o que lhes permite se posicionar nas relações sociais. E a interação com o conhecimento, 
nessa esteira de sentidos, pode ser considerada uma forma de libertação, já que pode possibilitar aquilo que RL chama de ter um lugar ao sol. A evidência é de que os sujeitos que melhor se impõem, ou seja, que fazem melhor uso de sua interação com o conhecimento, são aqueles que alcançam o almejado poder e reconhecimento, ou, como se diz, "vencem na vida". Configura-se, dessa forma, uma terceira representação de escrita nos dados: a de escrita como instrumento de poder.

Passemos, agora, à leitura discursiva dos recortes RD4, RD5 e RD6, relativos à fala do sujeito RB (escritor) ${ }^{10}$. Em RD4, temos sua resposta à questão n ${ }^{0} 5$ do nosso roteiro: Como você vê o espaço da escrita no mundo contemporâneo em relação às outras linguagens (como imagem e som, por exemplo)? Como nossa geração e coleta de dados foram realizadas por meio de entrevista semiestruturada, tínhamos abertura e flexibilidade para acrescentar, suprimir e/ou realizar desdobramentos nas perguntas previamente traçadas como roteiro. Assim, considerando o desenrolar da conversa, a questão $n^{\circ} 5$ foi reformulada no momento da entrevista, como se poderá ver abaixo. Já no caso de RD5, foi acrescentada outra pergunta que não havia sido prevista. Por fim, em RD6, temos uma resposta à questão $n^{\circ} 18$ do roteiro (Você gostaria de dizer algo a mais acerca de nossa pesquisa, mais especificamente desta temática?). Vejamos:

(RD4) RB (escritor):

P: E como é que você vê o espaço da escrita no mundo contemporâneo em relação a outras linguagens (+) uso de computador(+) à imagem(+) à internet(+) ao som? Como que você vê a escrita toda nesse meio?

RB: Eu acho que ela [a internet] criou uma oportunidade maior $(+)$ porque antes $(+)$ quando não tinha internet (+) não tinha computador (+) né? 0 meio de você fazer sua escrita chegar ao outro era um pouco mais difícil (+) e agora ela é um pouco mais fácil (+) tanto é que eu consegui o meu público maior por conta da internet (+) se dependesse do boca a boca apenas $(+)$ num teria sido tão grande quanto foi.

(RD5) RB(escritor):

P: E quando você escreve (+) você pensa em um público leitor? Ou você escreve simplesmente...?

RB: Quando eu escolho o tema (+) quando eu escolho o tema eu penso no públicoalvo (+) mas eu não penso no público quando eu estou escrevendo sobre aquele tema (+) porque eu acho que eles não devem palpitar sobre o que você deve ou

10 RB é escritora de contos e romances, auxiliar administrativo em empresa privada e graduanda do curso de Artes Visuais. 
não escrever "Ah (+) aquela cena você devia fazer assim (+) aquela cena você deveria fazer aquilo" (+) eu acho que não $(+)$ eu acho que eles têm que $(+)$ se eles tão gostando do que eu tô escrevendo $(+)$ eles têm que aceitar aquilo que você escreveu.

(RD6) RB (escritor):

P: Tem alguma coisa (+) assim (+) relacionada à escrita que te marcou durante a sua vida?

RB: Minha homenagem do SESC /.../ Foi a primeira. Foi o primeiro prêmio (+) assim $(+)$ que eu ganhei. E foi $(+)$ assim $(+)$ bem surpresa $(+)$ quando me ligaram pedindo pra eu comparecer $(+)$ e foi o que me marcou mesmo. Vou sempre lembrar. Foi bem importante pra mim.

Em RD4, é possível perceber que o sujeito RB, ao assumir o posicionamento enunciativo de escritor de obras literárias, seleciona e discursiviza algumas palavras relacionadas justamente à questão do reconhecimento pelo seu trabalho com a escrita, algo que, a nosso ver, está intrinsecamente relacionado à questão do empoderamento possibilitado pela expertise de conhecimento dessa modalidade da língua, conforme apontado na fala de $R L$ (também escritor). Do dizer de que a internet lhe proporcionou uma oportunidade maior, emerge um sujeito atravessado ideologicamente, que assume a posição de escritor de obras literárias e que constrói seu discurso discorrendo sobre a importância do reconhecimento alheio sobre seu trabalho e sua habilidade com a própria língua. Assim, por meio da expressão oportunidade maior, suspendemos a evidência de que há tempos o escritor de obras literárias não vinha tendo grandes oportunidades para que fosse lido e até mesmo reconhecido por seu trabalho.

Pensando na relação entre produção e recepção da escrita, Candido (2011) considera que o público leitor é condição essencial e mediadora para que o escritor/autor adquira consciência sobre si mesmo e sobre sua própria obra, sendo que a reação do outro (mesmo que mínima ou até ausente) pode incidir fundamentalmente sobre o trabalho de escritura: "o reconhecimento da posição escritor (a aceitação das suas ideias ou da sua técnica, a remuneração do seu trabalho) depende da aceitação da sua obra, por parte do público" (CANDIDO, 2011, p. 87). Sem público, continua o estudioso, não há ponto de referência para que aquele que escreve se constitua como autor/escritor, pois, nesta perspectiva, "escrever é propiciar a manifestação alheia, em que a nossa imagem se revela a nós mesmos" (CANDIDO, 2011, p. 86). Então, ainda que o escritor despreze a importância desse leitor, assim como faz RB (escritor) em RD5 - dizendo que não pensa no público quando está escrevendo e que seus leitores não devem palpitar sobre aquilo que escreve (eles não devem palpitar sobre o que você deve ou não escrever), mas sim aceitar ou não a sua obra (eles têm que aceitar aquilo que você escreveu)-, "está, na 
verdade rejeitando determinado tipo de leitor insatisfatório e reservando-se para o leitor ideal em que a obra encontrará verdadeira ressonância" (CANDIDO, 2011, p. 86).

Percebe-se, nos dados, como é forte essa ideia de que o escritor é dependente do público leitor, muito embora o sujeito RB afirme que para escrever lhe seja suficiente apenas as suas próprias ideias, os seus próprios sonhos e a sua satisfação relativamente ao próprio ato criador. Mesmo quando diz que as opiniões de seus leitores não alteram a produção de sua obra e a orientação de sua escrita, na verdade, a reação do leitor (ideal ou real) já está definindo a sua conduta enquanto escritor. E isso pode ser evidenciado em RD4 e RD6, quando RB afirma que a internet tem lhe possibilitado maior reconhecimento, e, consequentemente, empoderamento pela escrita. Percebemos a questão do poder relacionado à escrita emergir também na fala de RB, em RD4, ao relatar ter sido reconhecido por seus leitores como escritor de obras literárias (tanto é que eu consegui o meu público) e, em RD6, ao discorrer sobre a importância que significou sua primeira homenagem com a premiação enquanto escritor (Minha homenagem /.../ Foi a primeira. [...]. Foi bem importante pra mim). Conforme pontua Candido (2011, p. 87), "escritor e obra constituem, pois, um par solidário, funcionalmente vinculado ao público", de modo que o reconhecimento por parte desse público torna-se essencial para o crescimento do próprio escritor.

Ainda sobre tais questões, analisemos, agora, a fala do sujeito CE (publicitário) ${ }^{11} \mathrm{em}$ resposta a questão $n^{0} 11$ do roteiro:

(RD7) CE (publicitário):

P: Você utiliza a escrita digital? Quais e em quais ocasiões?

CE: Sim (+) com certeza (+) meu trabalho é todo feito através do computador (+) é aquela história de adequação ao contexto atual (+) hoje (+) não usar mídias digitais pode ser perda de tempo e também de dinheiro né (+) fundamental dominar essas técnicas $(+)$ inclusive $(+)$ hoje as publicidades on-line são até mais interessantes $(+)$ podem chegar ao cliente com mais rapidez $(+)$ pode haver um retorno maior $e$ mais eficaz (+) uma grande parcela da nossa sociedade utiliza a internet $(+)$ as redes sociais e tal $(+)$ então fazer publicidade através desses meios é algo que $(+)$ penso que pode atingir mais pessoas $(+)$ e em um curto espaço de tempo $(+)$ que gera lucro né $(+)$ trabalhamos com isso $(+)$ pode-se fazer publicidade por meio de widgets em celulares e computadores, áudio e vídeo (+) como nos canais do YouTube $(+)$ games marketing $(+)$ fazer publicidade por meio dos jogos eletrônicos em celular $(+)$ de redes sociais $(+)$ vish são infinitas possibilidades $(+)$ eu procuro utilizá-las $\mathrm{sim} / . . . /$

11Publicitário em empresa privada. Graduado em Design Gráfico e especialista em Animação em mídias digitais. 
Vale notar que, enquanto o sujeito RB (escritor) formula seu dizer apontando para a importância de um público leitor (O meio de você fazer sua escrita chegar ao outro era um pouco mais difíci), CE (publicitário) salienta, em RD7, a necessidade de alcançar e agradar a um público consumidor (chegar ao cliente), já que seu trabalho com a escrita pode ou não conduzir ao lucro. Certamente isso se deve ao fato de que, ao escrever profissionalmente para públicos distintos, cada um dos entrevistados assume uma determinada posiçãosujeito. Mas independentemente de qual seja o posicionamento enunciativo de quem escreve, emerge na fala de ambos esses sujeitos uma quarta representação: a de escrita como prática dependente do leitor.

A par disso, em ambos os recortes, entrevimos, ainda, uma última representação de escrita: como modalidade de língua veiculada pela internet. Muito embora não disponhamos de dados estatísticos sobre os principais modos de uso da língua, o oral e o escrito, na civilização contemporânea, é fato indiscutível que a escrita vem tomando espaço cada vez maior nas formas de comunicação entre os falantes, sobretudo com o advento da internet e a vertiginosa evolução das tecnologias digitais de informação e comunicação. Isso aparece em dois dos recortes apresentados, em que os sujeitos mencionam o impacto da internet em seus campos profissionais: em RD4 ("ela [a internet] criou uma oportunidade maior") e em RD7 ("meu trabalho é todo feito através do computador; uma grande parcela da nossa sociedade utiliza a internet"). A adjetivação por meio de maior (RD4), e de todo e grande (RD7) superdimensiona esse papel da internet enquanto suporte de linguagem, incluindo, com relevância, a escrita. Conforme Chartier (1998), com a expansão da internet e das tecnologias digitais de informação e comunicação, a escrita tem demandado diferentes habilidades e práticas de letramento, ao passo que pode se localizar em diversos suportes, atingindo ainda mais leitores/consumidores. É por isso que RB (escritor) e CE (publicitário) apontam para as consequências do impacto da internet em suas vidas: tanto é que eu consegui o meu público maior por conta da internet (RB); hoje (+) não usar mídias digitais pode ser perda de tempo e também de dinheiro (CE). Com a apresentação dessa última representação, encerramos, então, nossa breve análise.

\section{Em direção a outras representações}

Quando nos propusemos a investigar as representações de escrita na formação social extraescolar de utilização da linguagem, tínhamos a hipótese de que o imaginário discursivo estaria relacionado à ideia de norma padrão, em decorrência da influência ideológica do universo escolar na vida dos sujeitos entrevistados. Entretanto, contrariamente ao esperado, emergiram, em seus dizeres, representações relacionadas à língua fluida, ou seja, às práticas situadas de utilização da leitura e da escrita, para eles mais relevantes e significativas que as supostamente relacionadas ao domínio formal da língua. Entendemos, pois, que ao visualizarmos a categoria Letramento como a mais recorrente e abrangente em nossos dados, encontramos também uma representaçãochave de escrita sustentadora de todas as demais. 
Consideramos, então, que todas as representações às quais chegamos emergem da ideia de que escrever se constitui como prática viva de utilização da língua, algo bem mais abrangente e significativo do que a nossa hipótese inicial previa, já que apostávamos na recorrência de representações de escrita que envolvessem normas e coerções de uma língua imaginária, de uma língua-sistema como conceitua Orlandi (1988). Contudo, surpreende-nos perceber que o que prevalece é a noção de língua fluida, algo que, segundo nos parece, se articula muito bem com o conceito de letramento (KLEIMAN, 1995; SOARES, 1998). Conforme pontua Orlandi (1988, p. 34), isto que chamamos de língua fluida é algo que podemos observar e reconhecer ao focalizarmos "os processos discursivos, através da história da constituição de formas e sentidos, tomando os textos como unidades (significativas) de análise, no contexto de sua produção". E é por meio dessa língua fluida que desenvolvemos nossas práticas discursivas e ocorrem os eventos de letramento.

Resta-nos, contudo, proceder à sistematização das demais categorias por nós vislumbradas em nosso percurso analítico maior, as quais serão investigadas no decorrer da pesquisa em que o presente trabalho se insere. Porém, já nos é possível entrever que as demais categorias que emergiram deste nosso primeiro gesto interpretativo (Língua Imaginária x Língua Fluida; Ensino/Aprendizagem) podem se justificar justamente em função desta a que ora nos referimos e que pode, inclusive, estar a sustentá-las.

\section{REFERÊNCIAS}

ANTUNES, I. Aula de português: encontro e interação. São Paulo: Parábola Editorial, 2003.

AGUSTINI, C. L. H.; GRIGOLETO, E. Escrita, alteridade e autoria em Análise do Discurso. Matraga, Rio de Janeiro, v. 15, n. 22, p. 145-156, jan./jun. 2008.

AUROUX, S. A filosofia da linguagem. Tradução José Horta Nunes. Campinas: Editora da UNICAMP, 1998.

BARTON, D.; HAMILTON, M. Local literacies. London: Routledge, 2000.

CANDIDO, A. Literatura e sociedade. 12. ed. Rio de Janeiro: Ouro Sobre Azul, 2011.

CORRÊA, M. L. G. O modo heterogêneo de constituição da escrita. São Paulo: Martins Fontes, 2004.

DIONÍSIO, M. de L. T. Literacias em contexto de intervenção pedagógica: um exemplo sustentado nos Novos Estudos de Literacia. Educação (UFSM), Santa Maria, v. 32, n. 1, p.97-108, jan. 2007. 
FERREIRA, A. B. H. Mini Aurélio: o dicionário da língua portuguesa. 8. ed. Curitiba: Positivo, 2010. Coordenação Marina Baird Ferreira.

FISCHER, A. A construção de letramentos na esfera acadêmica. 2007. Tese (Doutorado em Linguística) - Universidade Federal de Santa Catarina, Florianópolis, 2007. Disponível em: http://repositorio.ufsc.br/xmlui/handle/123456789/89764. Acesso em: 02 jan. 2018.

FOUCAULT, M. Microfísica do poder. 23. ed. São Paulo: Graal, 2004.

GNERRE, M. Linguagem, Escrita e Poder. 3. ed. São Paulo: Livraria Martins Fontes, 1991.

INDURSKY, F. O texto nos estudos da linguagem: especificidades e limites. In: ORLANDI, E. P.; LAGAZI-RODRIGUES, S. Discurso e textualidade. 2.ed. Campinas: Pontes, 2010. p. 33-80.

KLEIMAN, A. B. Modelos de letramentos e as práticas de alfabetização na escola. In: KLEIMAN, A. B. Os significados do letramento: uma nova perspectiva sobre a prática social da escrita. Campinas: Mercado de Letras, 1995. p. 15-61. (Coleção Letramento, Educação e Sociedade)

LAGAZZI-RODRIGUES, S. Texto e autoria. In: ORLANDI, E. P.; LAGAZZI-RODRIGUES, S. Introdução às ciências da linguagem: discurso e textualidade. 2. ed. Campinas: Pontes, 2010. p. 81-104.

MARCUSCHI, L. A. Análise da Conversação. São Paulo: Ática, 1986.

MARCUSCHI, L. A. Letramento e oralidade no contexto das práticas sociais e eventos comunicativos. In: SIGNORINI, I. (org.). Investigando a relação oral/escrito e as teorias do letramento. Campinas: Mercado de Letras, 2001. p. 23-50. (Coleção Ideias sobre Linguagem)

ORLANDI, E. A Linguagem e seu funcionamento: as formas do discurso. 6. ed. Campinas: Pontes, 2011.

ORLANDI, E. Análise de Discurso: princípios e procedimentos. 7. ed. Campinas: Pontes, 2007.

ORLANDI, E.; SOUZA, T. C. C. de. A língua imaginária e a língua fluida: dois métodos de trabalho com a linguagem. In: ORLANDI, E. P. (org.).Política linguística na América Latina. Campinas: Pontes, 1988. p. 27-40. 
PÊCHEUX, M. Semântica e discurso: uma crítica à afirmação do óbvio. 2. ed. Campinas: Editora da Unicamp, 1995 [1975].

SOARES, M. B. Letramento: um tema em três gêneros. Belo Horizonte: Autêntica, 1998.

STREET, B. V. Literacy in theory and practice. Cambridge: Cambridge University Press, 1984.

TFOUNI, L. V. Letramento e Alfabetização. 9. ed. São Paulo: Cortez, 2010. 